\title{
An Analysis Of Rater Error In Recruitment And Selection Process Of IT Organizations
}

\author{
Z. B. Junaid \\ Economics Academy \\ Wuhan, China \\ Muhammad Siddique \\ Pakistan Navy School of Logistics \\ PNS Karsaz, Karachi \\ Mariya Baig \\ Department of Examination \\ University of Karachi
}

\begin{abstract}
This paper attempts to study the extent to which rater error is prevalent in recruitment and selection process in Islamabad based Information Technology (IT) organizations. The study observed, evaluated and analyzed complete recruitment process of the 03 selected organizations to find out any conscious or unconscious activity of rater error during the selection process. The study employed qualitative research methodology in which whole selection process was monitored in person, all recruitment forms and documents were studied, unstructured interviews were conducted with the Chief Operating Officers, the Human Resource managers, the technical managers of the organizations and even the candidates. After thorough analysis, the findings of the study reveal that rater errors exist in all of the three organizations, influenced by several conscious and unconscious factors. Results show that stereotyping, halo effect, contrast effect, similarto-me effect and first impression effect were prevalent in the organizations which undermine the objective evaluation of candidates to a greater extent. The study recommends the organizations should pursue rater training programs of the all managers, executives involved in the recruitment process and conducting panel interviews for minimizing the rater errors.
\end{abstract}

Keywords: Rater Error, Recruitment, Selection Interviews.
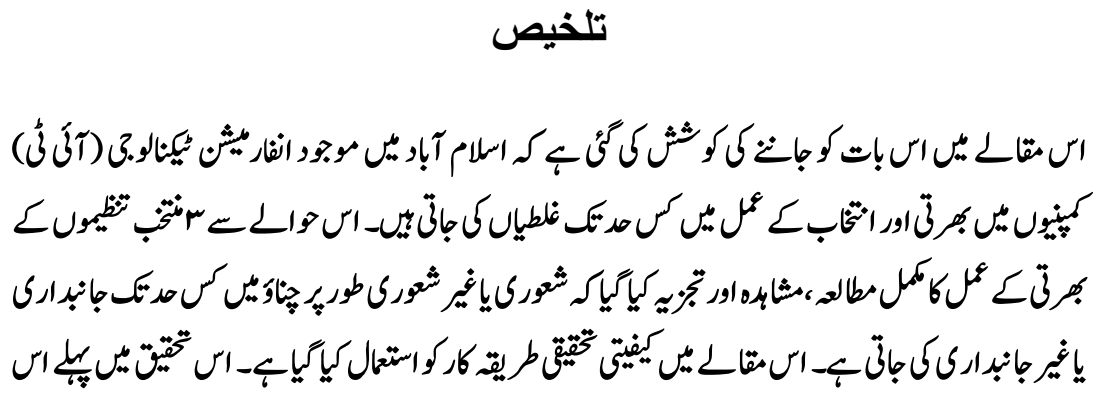


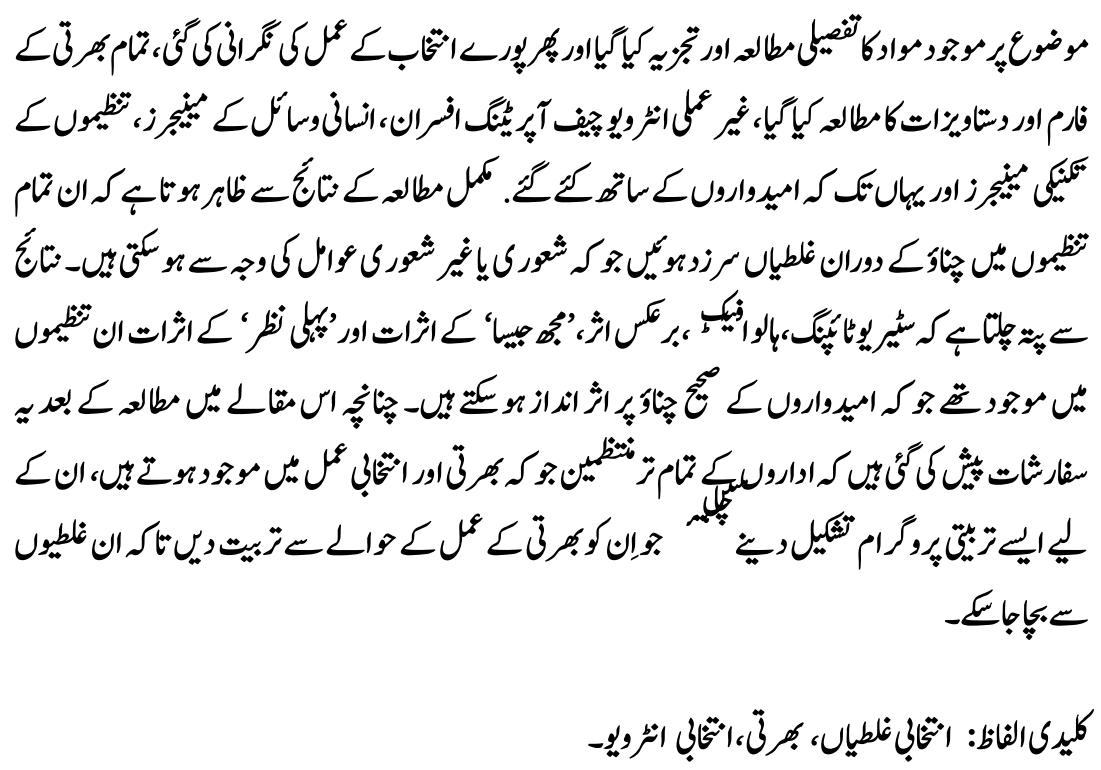

\section{Introduction}

The increase in competition and technological advancements has made organizations to fight for their survival. To survive in the market, companies specially the Information Technology (IT) organizations need to develop and grow internally as well as externally. Maital(1994) believes that employees are the most strategic asset of an organization and they can gain competitive advantage by appropriately organizing and training. As the business environment is changing, organizations have started looking at Human resource as a resource that can be a source of value and competitive advantage. Since, human capital is the central resource of any organization, so nowadays organizations are looking forward to get the best possible workforce for themselves in order to achieve competitive advantage (Seyyadjavadin \& Zadeh, 2009). Therefore, besides focusing on making the Human Resource Departments more strategic in nature, organizations are laying greater emphasis on recruitment and selection function of HR.

The recruitment and selection function of HR is the most important and basic brick for any organization. If an organization is able to hire the right men for the right job, then half of the task is already done (Sparrow, 2007). As an employer, the goal is to get the best possible human capital and then provide them opportunity to do work for getting better results. Therefore, it is important to prepare well defined job design and job description, advertise it at the places where best possible Human Capital is expected and then hire carefully (Ahmad \& Schroeder, 2002). The last step in hiring of people is very important. This is the point where organizations commit most of the mistakes. Selection of the right selection board for the selection of right potential employees is very important (Shivdasani \& Yermack, 1999). This 
very sentence means that organization should carefully select the board or the managers who will carry out the interviews of the potential candidates (Rahat \& Hazan, 2001). The people who will be selecting the potential candidates should be experienced, well versed with the requirement of the particular position, should have knowledge of the skills that are required in the potential candidates and should be well trained recruiters and selectors so that they don't commit rater error (Lee, 1985).

Rater error in recruitment processes and selection process has been an extensively researched area in the field of Human Resource Management (Anderson, \& Shackleton, 1986). Rater errors are judgmental errors that occur when an individual evaluates performance of others in an organizational setting in specific or, generally, in any other situation (Hoyt, 2000). These errors mainly occur unconsciously and sometimes consciously as well. In both the cases, these errors should be avoided in recruitment and selection processes as they can lead to erroneous selection of candidates which may lead to poor organizational performance. It is an important unit of analysis in performance management in specific; and social perception, in general. In return, performance management and social perception have significant implications on organization's human capital and on the organization as well (Bernardin, \& Buckley, 1981).

\section{Purpose of the Study}

This work attempts to study the extent to which rater error is prevalent in the Recruitment and Selection (R\&S) process of Information Technology organizations. The study is aimed at evaluating the extent to which the recruiters consciously or unconsciously make rater errors in their recruitment processes generally and in the selection interviews specifically.

\section{Scope of the Study}

This study selected the Information Technology organizations which are involved in software developments. The selection of IT organizations is based on the fact that these organizations tend to focus more on the technical skills of the individuals rather than cognitive and interpersonal skills during the selection. The candidates are mainly evaluated on the technical skills and general managerial skills, hence rater errors are more common in these organizations. Therefore this study selected IT organizations for the analysis.

\section{Limitations of the Study}

The foremost limitation of the study is the limited access to IT organizations. This is because of the fact that most organizations does not allow to study, inspect and 
observe their recruitment processes. Initially more than 15 organizations were approached to carry out the research but only 3 were allowed to conduct the study so that their names and official documents must not be disclosed. This is considered a major limitation of the study as the sample size should be greater to have accurate results.

\section{Literature Review}

Nowadays, competitive advantage of an organization is the key towards its success. This competitive edge does not only lie in differentiating a product or service or in becoming the low cost leader but also lies in the quality of human capital that an organization possesses (Barney, 2007). The traditional emphasis was on the equipment of the organization that would give an organization a competitive edge. However in the present era this competitive edge can be gain more effectively by developing employees' skills and training them (Gutierrez, Barrales \& Kaynak, 2018). This is where from which the managers got the idea of focusing and investing in HR by aligning their HR strategy with the business strategy. In short, if organization has the best of best employees, then the management will be able to consolidate their skills into competencies which can be beneficial for the overall winning strategy. Hence, competitive advantage can only be obtained with a high quality workforce that enables organizations to compete on the basis of market responsiveness, product and service quality, differentiated products and technological innovation (Formby, Malhotra \& Ahire, 2018). It is now widely agreed upon the fact that in the present times human capital is the most important asset of an organization and the most important source of competitive advantage. This particular competitive advantage can be achieved by the organizations in two ways; either by (1) training the employees, or (2) by hiring the most suitable workforce (Hamilton\& Davison, 2018).Therefore, mostly organizations are trying to gain the competitive advantage by recruiting the best available human capital and then by efficiently managing this resource. The recruiters are looking to hire capable and committed employees who can be aligned with organizational values, who already posses the desired skills for the business and have the ability to work in a way which avoids conflicts between different functions or departmental work (Hilton, 2000). This is only possible when the recruiters select the best possible candidate. If organizations are able to effectively manage their recruitment and selection function, they will be able to find the best employees for the organization (Sparrow, 2007). This largely depends on the selection committee, the interviewers and the selectors. The selection committee should be trained, well versed with the requirements and should be unbiased when conducting the interviews during selection procedure (Van, Bakker \& Bakker, 2002). They should not commit conscious or unconscious judgment errors during the recruitment and selection process. These judgmental errors are also known as rater errors (Tziner \& Rabenu, 2018). 
Rater errors are judgmental errors that occur when an individual evaluates performance of others in an organizational setting in specific or generally (Klimoski \& London, 1974). Study of the literature reveals that personal perception can impact the rating of the interviewee. This sub-conscious thinking which affects the rating of the candidate is known as rater's error (Tweedie, Wild, \& Martinov, 2018). Usually the individual who is committing rater error is unaware of the fact that he or she is falling prey of this mistake (Royal \& Hecker, 2016). In other words, when an individual or a team rates the performance of another person with a closed and preset mind, there is a possibility that the rater may commit a rater error in the evaluation. So it can be redefined as the inaccuracy that is forced into an employee's appraisal which resulted from a bias, but not from the employee's performance (Poon, 2004). A range of rater errors have been identified by the researchers as a result of deep understanding of the phenomenon; Social Perception. Social perception is basically the study of how human beings tend to form pre-assumed ideas, impressions and inferences about others based on limited clues (Snyder, Tanke, \& Berscheid, 1977). When these perceptions are wrongly used to gather information about the interviewees during the selection processes, they are termed as rater errors (Fletcher, 2001). Social Perception and rater errors have been an area of research from the early twentieth century. However, there is less significant literature available in more recent years. The literature available on rater error is very old and less work has been carried out in the recent decades. The classic paper of Thorndike (1920) laid the foundation of rater error in performance appraisal. He was the first to coin the term "halo error' or 'halo effect'. He described the error as the rater's tendency to rate a interviewee - in general - as rather good or inferior and to judge his/her separate qualities as by this general feeling. He studied how commanding officers tend to correlate the physique of soldiers with intelligence, leadership and character.

Dion, Berscheild and Walster (1972) in their study on college graduates found that more attractive individuals were associated with more socially desirable traits such as kindness and honesty. Moreover, the study found that attractive individuals were more likely to find better jobs than average looking persons. Nisbett and Wilson (1977) identified that the global evaluations of a person can induce altered evaluations of the person's attributes, even when there is sufficient information available to allow for independent assessments of them.

As depicted in figure 1, there are three types of rater biases which may skew the objective evaluations to either more preferable than warranted (leniency error); less preferable than warranted (severity/strictness bias); or round-about evaluation (central tendency). Studies have identified such rater errors in supervisory evaluations and letters of recommendation during graduate training programs (Siskind, 1966; Solway, Mock, Bostick and Reck, 1977; Miller and Van Rybroek, 1988). Miller and Rybroek (1988) specifically found that the letters of 
recommendation written on behalf of internship applicants are often very exaggerated and unrealistic and decisions based on such recommendations are not objective.

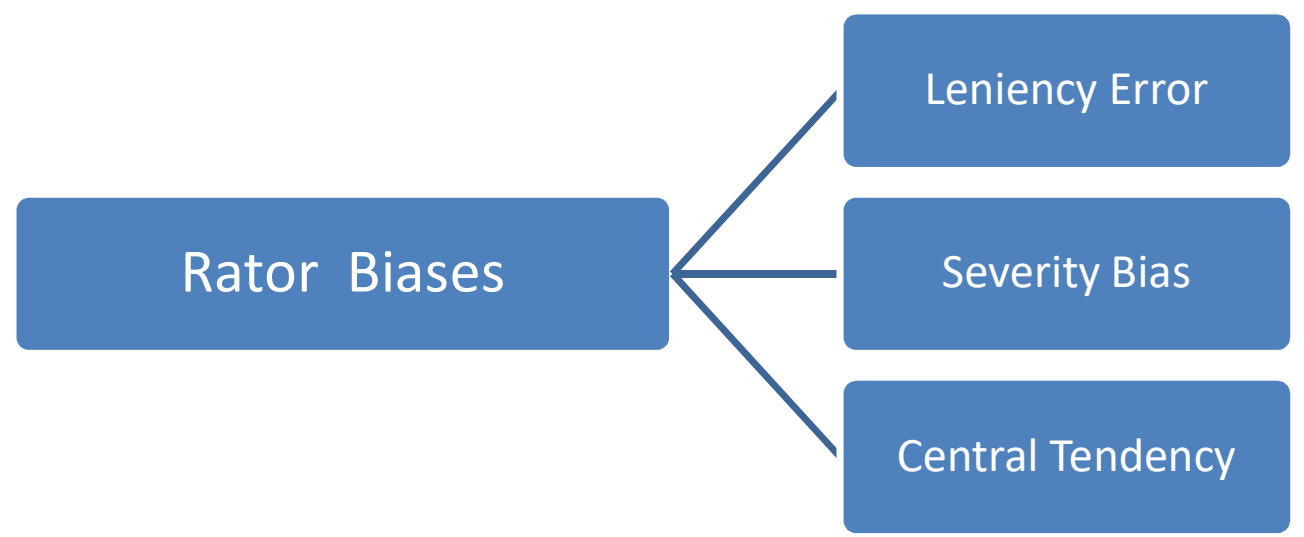

Figure 1 -Types of Rater Biases

Rand and Wexly (1975) studied the 'similar-to-me' tendency in the ratings of interviewers in simulated job interviews of 160 subjects $($ Blacks $=80$; Whites $=$ 80 ). They found that that biographical similarity of interviewer and applicant led to higher ratings of the candidate's job suitability and other personal characteristics.

Anderson and Shackleton (1990) studied the influence of nonverbal behavior of the interviewee upon the impression formation of the interviewer. The study focused on finding of the tendencies of similar-to-me effect, personal liking bias and prototype bias. Thirty-eight graduate interviewers participated in the study and completed assessments on 330 interviewees for 14 diverse occupational groups. The decisions of interviewers were found to be influenced by the impressions of interviewee.

Lin, Dobbins, and Farh (1992) examined the effects of interviewer and interviewee race and age similarity on interview outcomes under two different interview formats: a conventional structured panel interview and a situational panel interview. A total of 2,805 applicants were interviewed. The panels consisted of same, mixed, or different-race and age groups. Analysis revealed stronger same-race effects with the conventional structured interview than with the situational interview. No age similarity effects were detected with either interview procedure.

Avolio and Barrett (1987) studied the effects of, both, positive and negative age stereotyping on subjects' ratings. The study found that the participant interviewers gave higher ratings to younger candidates as compared to an older one with the same qualifications. 


\section{Common Rater Errors}

Study of the literature reveals that there are many rater errors which can be seen in different settings. However, pertinent rater errors are more relevant to this study, summarized below:

Stereotyping is commonly held belief, notion, or generalization about certain group based upon certain presuppositions or imagined traits(Oakes, Haslam \& Turner, 1994). For example, a positive stereotype about Brazilians is that All Brazilians are good footballers.

Halo Effect is the tendency to generalize a single outstanding trait about a person over his/ her other traits or personality (Murphy, Jako \& Anhalt, 1993).

Leniency Error is the tendency to give inflated evaluation above what the ratee actually was supposed to receive. In turn, an average perform may seem outstanding and a poor performer tends to be average (Bernardin, 1978).

Severity Error is the tendency to evaluate every candidate very conservatively and assigning evaluation below what a ratee was supposed to receive (Robiner et al., 1998).

Round About Evaluation is the evaluator's tendency to rate every one as average regardless of individual differences in performance (Pulakos et al., 1996).

Contrast Effect is the tendency of the rater to compare the individual with other rates rather than the job description, specifications, and/or job performance (Bower, 1961).

Similar-to-Me Effect occurs when the raters assign more favorable evaluations to the ratees whom they perceive as being similar to them in certain aspects such as ethnicity, values, beliefs, likes, political affiliations etc (Rand \& Wexley, 1975).

First Impression Error occurs when the rater is influenced by the initial favourable or unfavourable judgments about a ratee and ignores any further information that may even contradict with that judgment (Hamilton, Katz \& Leirer, 1980).

\section{Methodology}

In order to carry out the research, this study selected 3 Islamabad based Information Technology companies having 50 to 70 employees. These 
organizations were selected on the criteria of their work that is software development, web development services and IT infrastructure development services. All these organizations have been established for more than 8 years. In order to keep the privacy and to respect the internal policies of these organizations, identity of the 3 organizations is not being disclosed here. After selection of the organizations, data collection and analysis was carried out.

This study covered complete recruitment processes of the selected IT organizations; all the documents and forms used in their R\&S and also observed the selection interviews. Furthermore, pre and post interviews of the interviewers and the interviewees were also carried out to find out rater errors. The observations of these interviews were later analyzed in detail.

\section{Data Collection}

Due to the nature of the study and the methodology of the paper, meaningful and careful data collection was an important step to fully understand the behavior and its underlying reasons. Therefore both primary and secondary sources have been utilized in collecting the data for the study. Primary data was collected by carrying out interviews of COO, HR managers, IT managers and recruiters both before and after the selection interviews. The interviews were unstructured which helped in collecting information regarding every aspect of the respective department.

Secondary data was collected from two sources which are as follows. First, relevant literature, publications and studies were reviewed in order to get in-depth information on the topic. Second, in order to get further insight of the recruitment and selection procedures of these organizations, company's websites and documents were used to collect data. All the collected data was analyzed to get the results.

\section{Data Analysis}

The qualitative analysis of data was carried out extensively. The observations were analyzed based on the study of the literature review. Moreover, the actual selection interviews were analyzed against the company policies/ recruitment procedures in following ways:

- Evaluation of Recruitment Documents

- Interviews with the Human Resource Managers, Technical Managers, and Chief Operating Officers (COO) of the organizations

- In person silent observation of selection interviews

- Interviews of candidates/Interviewees 
Detail of each step is described below:

\section{Evaluation of Recruitment Documents}

Mainly two types of documents were assessed in each organization. Although names of these documents differ in every organization but based on the nature of the documents, we can summarize them in the following two categories:

- Application Forms for Employment

- Candidate's Evaluation Forms

As per the recruitment policy of these organizations, the candidates have to fill in an application form for employment. The form contains a personal information section, a background information section and a questionnaire regarding the behavioural dimensions of a candidate's personality. During the evaluation, prime focus of the study was on questionnaire. The study analyzed and marked the questions which were related to the study for example, the questions which could lead to making a positive first impression or short term learning errors. This study also analyzed the personal data section and educational/ work background section which could lead to similar-to-me effect.

All the managers had an evaluation form. During the examination of these forms it was found that many evaluators check marked over the competencies on candidates were graded in each interview and were being assessed.

\section{Interview with the Managers (HR, Technical, COO)}

In two organizations separate interviews were carried out by HR, Technical Team and the COOs of the candidates while in one organization panel interviews were conducted. Moreover, informal interview sessions with Human Resource Managers, Technical managers, and COOs were also carried out at two different intervals i.e.:

- Pre- interview session

- Post-interview session

\section{Pre-Interview Session}

Before starting the selection interviews, the HR managers, Technical managers, and the COOs were interviewed in an informal setting. The prime objective during these interviews was to informally discuss the recruitment and selection procedures, elements of job design (job description / job specifications), training and development programs and compensation system. The Human Resource 
managers had to take elementary interview, whereas the technical staff has to take an in-depth interview regarding the skills and qualification of interviewee. The COOs has to make final decision whether to hire a candidate or not in the final interview. It is observed that on many occasions the interviewers discusses the candidates on their CVs and commented about them. This lead to formation of a general perception about the interviewee without ratee being assessed yet.

\section{Post-Interview Session}

Once the candidates are interviewed, discussion and cross-questioning session with all the managers is conducted separately. They ask about their perceptions of the candidates regarding their rejection and selection criteria.

\section{Observation of Selection Interviews}

During the selection interviews, it is observed that the candidates are also judged immediately based on following factors:

- Appearance

- Confidence

- Outreach

- Communication skills

- Behavior

The interviewers were keenly observed for identifying any rater error they would make while evaluating the interviewees. Comparisons are made about what the interviewers said prior to the interview and what they actually did during the interviews.

\section{Interview of Interviewees/Candidates}

In the end, for the purpose of our analysis, we interviewed the candidates and asked for their opinion of the interview; as what they thing of the interviewers. This data help the study to compare the actual behaviour of the candidates and their perception about their performance. Their opinion about the managers also helped to rate managers as tough, strict, lenient or friendly.

\section{Findings}

Based on the analysis of the collected data, this study substantiated that the raters evaluation is influenced by several conscious and unconscious errors. Pertinent findings are discussed in detail as follows: 


\section{Stereotyping}

The findings of the current study are consistent with those of previous works which found stereotyping effects in organizations. This study has observed following stereotypes:

\section{Ethnicity}

Ethnic groups including race, cultural, national and tribal segments are a major aspects of stereotyping. In this study, it was observed that during an interview one of the candidate belonged to Khyber Pakhtunkhwa (KPK), based upon these findings the interviewer straightaway related the interviewee with the particular attributes famous for the KPK people. The interviewer told that KPK people are aggressive so you must also be an aggressive person. The interviewee negated the concept and replied that "every individual is different and you cannot relate aggressiveness and anger to me as well". But the mind set of interviewer being stereotypical thinking did not change.

In fact this is very true that every individual is different and unique. We cannot stereotype people. Especially when we are in the hiring process, we tend to analyze people on the basis of generalized observations.

\section{Educational Background / Institute}

Another stereotype which was observed in the study is regarding the educational institute or background. During the interviews it was found that few of the interviewers were having a belief that if someone has studied from a particular institute, irrespective of his marks or score, he must be a very good professional. This is another example of stereotyping. Every student is different in his learning abilities and his performing capabilities. If three students have studied from a particular institute, it doesn't mean that they all are preferred just because of the brand name of the institute.

\section{Similar-To-Me Effect}

When an evaluator gives more favourable evaluations to people who are similar to the evaluator himself, in terms of background or attitudes, here is when similar-tome effect comes into action. Researchers have clearly shown that interviewers and supervisors have an unconscious tendency to favour people who are physically and professionally similar to them. This is very important aspect which holds women and minorities back in the working world. Mentors often select apprentices that are similar to themselves. This is very common in mentor and protégé ${ }^{1}$ relationship. In job interviewers, people tend to favour candidates who are like them. 
The current study found that similar to me effect also arises when interviewers seek a candidate who has been working in their previous organization. In one of the organization, the interviewers asked the candidate, "In which organization you have been working previously?" The interviewer replied with the name of an organization and suddenly interviewers tone changed with a sentence that, "Nice, It reminds me of my good old days. I also started my career from the same organization".

This study produced results which corroborate the findings of a great deal of the previous work in this field. This enunciates that interviewers while conducting interviews are sometimes unable to hide their own feelings. Judgment should be justified and correct. Personal feelings should be kept out.

\section{Why Similar-To Me-Effect Happens?}

There can be many reasons for why 'Similar to Me' effect happens. Firstly, it's from the evolution of human beings that we like to be in our own group. We prefer to be with those who are like us. In other words we tend to like people who are like us and tend to dislike people who are not like us.

Secondly, human beings want to be in a group which matches their value system. Every individual is related to a particular group. Every group is associated with certain values. And when a person observes theses values in any other person/ group, he tries to get attached/ associated with that particular group.

\section{Contrast Effect}

This study confirms that contrast effect is associated with the selection interviews. In this regards, three candidates were specifically focused by this study who were being evaluated at one of the organization. The first candidate was nervous, selfdoubting and was unable to express his point of view openly. The second candidate, on the other hand, was confident, demonstrated better communication skills and was having good body-language. When the second candidate was done with the interview, the interviewers starting comparing the two and developed an opinion that the second interviewee was better. Although he was not the right fit for the job as the technical managers commented but still interviewers starting contrasting the two and regarded the second interviewee as better.

\section{First impression Effect}

It was observed that the organizations asked each candidate to fill an employment form before coming for the interview. The form contain open-ended questions like, how do you manage stress in your daily work? How do you work under 
pressure? The candidates are given enough time to fill the form before the interview. Then they submit the form before coming to the interview. The HR manager then goes through the form and asks other questions from the candidate. This study found that there is a good first impression developed by the interviewer out of the answers given to those questions. Candidates with answers create a positive or a negative first impression in the mind of the interviewer and the impression remains there till the last. The manager behaves according to the perception he/she has developed in the his/her mind.

Because of the fact that we are involved in self fulfilling prophesies, what we have in our mind we tend to prove ourselves right and for that we are looking and registering only those information and events which are consistent and match to our expectation and perception. So the first impression whether good or bad in the start, remains there till the end and affects the rater either positive or negative.

\section{Halo Effect: Confidence Bias}

During the observation of interviews, it was seen that a halo error persisted in the evaluations in the form of confidence bias. Few of the interviewees preferred the candidates who appeared to be confident and stable as was the case of second candidate. On the other hand, managers refused the first candidate by regarding him as nervous and confused. It was a halo effect as they would generalize one single trait i.e. confidence over the whole personality of the candidate and used confidence as rejection rule.

\section{Strictness Bias}

The HR managers usually asked general and routine questions and the candidates regarded them as simple to answer. Moreover, they would give the candidate ample time to respond to a question. On the other hand, the technical interviewers asked very difficult questions from the interviewees as confirmed from them in the post-interview session. They asked eight to ten questions from each candidate and upon answering a question, they would asked another-and a more challenging-question in a particular programming area. They rated the candidates very low as well which confirmed of strictness bias in the interview process.

\section{Discussion and Conclusions}

Rater error results out of the perceptual imperfections and can be regarded as human error. However, an awareness of all types of rater error can help decrease its occurrences. The findings reveal that there existed a great deal of rater error in the organizations, stereotype, strictness bias, contrast effect, halo effect, similar- 
to-me and first impression effect were the forms in which rater error was identified in the selective organizations.

According to Nisbett and Wilson (1977), the interviewer must try to get as much information about the interviewee as possible and then go for an objective decision. Rater error results in hasty generalizations which can be fatal for the organization.

Sometimes the interviewer is influenced from a single positive or negative trait of the interviewee which might not even correspond to the job requirements. Such a generalization may result into inflated performance of a candidate, on the other hand, may underestimate the skills and talent of another. As it was observed in the experiment, that on few occasions evaluators judged the candidates on comparison basis i.e. comparing a candidate's performance with another one rather than the job requirements. Such evaluation is not only unfair for individual but also for organization as well. As it is not a good tool for evaluation. Comparison among candidates is not appropriate for objective evaluation. Evaluators must avoid it. It was observed that some of the evaluators rated candidates lower, to show that their evaluation process is very tough as this study discussed the analysis of technical interviewers; Technical managers rated the candidates very low and expressed themselves very strict in their evaluation process. It is again compromising objectivity and does not present a fair evaluation of the candidate.

Moreover, a candidate should be evaluated on the basis of job description and specifications rather than comparisons among candidates. Similarly, during performance appraisals, evaluators should rate the employees according to their current or prospective future assigned task which supposes to be done by them in actual job environment. According to the finding of this study, it will be more fruitful for both the organization and the prospective employees.

It is a famous saying that "first impression is the last impression and this saying was quite visible in the selected organizations. To rate an individual on first impression is hasty generalization and undermines objectivity and fair evaluation. Evaluators must be conscious about this effect and try to get rid of it so that he can evaluate an individual fairly and can select the candidate best suited to the organizational needs.

\section{Recommendations}

Following are some recommendations for the selected IT organizations in specific and other organizations in general: 
- Although it is not possible to rule out human error in any process but situation can be improved by creating awareness among the recruiters to be more conscious in avoiding these errors.

- Sometimes awareness is only required to reduce the effect but to be more effective, the organizations should conduct training sessions for their interviewers to reduce the social perception errors in selection interviews. Training interviewers in the critical evaluation of information obtained from the interviewee usually focuses on improving the decision making process of the interviewer by pointing out common decision errors and providing methods for overcoming these errors. Common errors observed were halo effect (rating across all performance dimensions influenced by the rating on one important dimension), similar to effect, contrast effect and first impression error.

- Training programs should use videos or simulated interviews. The interviewers should be shown actual scenarios of the interviews and then they should be warned about the possibility of any rater error being done from their side. In this way organizations can improve their recruitment processes and give better employees to the organization

- Panel interviews are good technique which can help to reduce the rater errors. It can help to increase the accuracy of information; ensure the objective evaluation and validity of assessment. Chances of subjective error are less in panel interviews as compared to individual interviews. A panel interview not only saves time but helps to make correct decisions. Furthermore, the same-race effects could be avoided by using mixed-race interview panels.

\section{Future Research}

This study found that the literature available on rater error is quite old. Less work has been done in the last couple of decades. Hence, there is a dire need that this area may be researched especially after the advancements in the recruitment and selection techniques and after implementation of enterprise resource planning softwares like SAP and My SAP. Moreover, the design of this study can be further implemented on other organizations to verify the results. It will be interesting to the result of other organizations which are not technology oriented.

\section{End Note}

1. Protégé: A young person who receives help, guidance, training, and support from somebody who is older and has more experience or influence. 


\section{References}

Ahmad, S. \& Schroeder, R. G. (2002). The Importance of Recruitment and Selection Process for Sustainability of Total Quality Management. International Journal of Quality \& Reliability Management, vol.19:5, pp.540-550.

Anderson, N. \& Shackleton, V. (1990). Decision Making in the Graduate Selection Interview: A Field Study. Journal of Occupational Psychology, vol.63:1, pp.63-76.

Anderson, N. \& Shackleton, V. (1986). Recruitment and selection: A review of developments in the 1980s. Personnel Review, vol.15:4, pp.19-26.

Avolio, B. J. \& Barrett, G. V. (1987). Effects of Age Stereotyping in a Simulated Interview. Psychology and Aging, vol.2:1, pp.56-63.

Barney, J. B. (2007). Gaining and Sustaining Competitive Advantage. Prentice Hall.

Bernardin, H. J. (1978). Effects of Rater Training on Leniency and Halo Errors in Student Ratings of Instructors. Journal of Applied Psychology, vol.63:3, p.301.

Bernardin, H.J., \& Buckley, M.R. (1981). Strategies of Rater Training. Academy of Management Review, vol.6:2, pp.205-212.

Bower, G. H. (1961). A Contrast Effect in Differential Conditioning. Journal of Experimental Psychology, vol.62:2, p.196.

Dion, K., Berscheid, E. \& Walster, E. (1972). What is Beautiful is Good. Journal of Personality and Social Psychology, vol.24:3, pp.285-290.

Fletcher, C. (2001). Performance Appraisal and Management: The Developing Research Agenda. Journal of Occupational and Organizational Psychology, vol.74:4, pp.473-487.

Formby, S. K., Malhotra, M. K. \& Ahire, S. L. (2018). The Complex Influences of Quality Management Leadership and Workforce Involvement on Manufacturing Firm Success. International Journal of Productivity and Performance Management, vol.67:3, pp.502-518.

Gutierrez-Gutierrez, L. J., Barrales-Molina, V., \& Kaynak, H. (2018). The role of human resource-related quality management practices in new product development: A dynamic capability perspective. International Journal of Operations \& Production Management, vol.38:1, pp.43-66. 
Hamilton, D. L., Katz, L. B., \& Leirer, V. O. (1980). Cognitive Representation of Personality Impressions: Organizational Processes in First Impression Formation. Journal of Personality and Social Psychology, vol.39:6, p. 1050 .

Hamilton, R. H. \& Davison, H. K. (2018). The Search for Skills: Knowledge Stars and Innovation in the Hiring Process. Business Horizons, vol.61:3, pp.409-419.

Hilton, D. (2000). Hiring and Retaining Top Talent to Attract and Keep the Best Employees, You have to be willing to invest both time and money. Credit Union Executive Journal, vol.40, pp.12-19.

Hoyt, W. T. (2000). Rater Bias in Psychological Research: When is it a problem and what can we do about it? Psychological methods, vol.5:1, p.64.

Klimoski, R. J. \& London, M. (1974). Role of the rater in performance appraisal. Journal of Applied Psychology, vol.59:4, p.445.

Lee, C. (1985). Increasing Performance Appraisal Effectiveness: Matching Task Types, Appraisal Process and rater Training. Academy of Management Review, vol.10:2, pp.322-331.

Lin, T., Dobbins, G. H. \& Farh, J. (1992). A Field Study of Race and Age Similarity Effects on Interview Ratings in Conventional and Situational Interviews. Journal of Applied Psychology, vol.77:3, pp.363-371.

Maital, S. (1994). Executive Economics: Ten Essential Tools for Managers. New York: Simon and Schuster.

Miller, R. K., Van Rybroek, G. J. (1988). Internship Letter of Recommendations. What are the Other 90\%? Professional Psychology: Research and Practice, vol.19:1, pp.115-117.

Murphy, K. R., Jako, R. A. \& Anhalt, R. L. (1993). Nature and Consequences of Halo Error: A Critical Analysis. Journal of Applied Psychology, vol.78:2, p.218.

Nisbett, R. E. \& Wilson, T. D. (1977). The Halo Effect: Evidence for Unconscious Alteration of Judgments. Journal of Personality and Social Psychology, vol.35:4, pp.250-256. 
Oakes, P. J., Haslam, S. A. \& Turner, J. C. (1994). Stereotyping and social reality. Blackwell Publishing.

Poon, J. M. (2004). Effects of Performance Appraisal Politics on Job Satisfaction and Turnover Intention. Personnel Review, vol.33:3, pp.322-334.

Pulakos, E. D., Schmitt, N., Whitney, D. \& Smith, M. (1996). Individual Differences in Interviewer Ratings: The Impact of Standardization, Consensus Discussion, and Sampling Error on the Validity of a Structured Interview. Personnel Psychology, vol.49:1, pp.85-102.

Rahat, G. \& Hazan, R. Y. (2001). Candidate Selection Methods: An Analytical Framework. Party Politics, vol.7:3, pp.297-322.

Rand, T. M. \& Wexley, K. N. (1975). Demonstration Of The Effect, "Similar To Me," in Simulated Employment Interviews. Psychological Reports, vol.36, pp.535-544.

Robiner, W. N., Saltzman, S. R., Hoberman, H. M., Semrud-Clikeman, M. \& Schirvar, J. A. (1998). Psychology supervisors' bias in evaluations and letters of recommendation. The Clinical Supervisor, vol.16:2, pp.49-72.

Royal, K. D. \& Hecker, K. G. (2016). Rater Errors in Clinical Performance Assessments. Journal of Veterinary Medical Education, vol.43:1, pp.5-8.

Seyyadjavadin, S. R., \& Zadeh, M. H. (2009). HR strategy and Its aligning with organizational strategy and human capabilities. Iranian Journal of Managment Studies, pp.5-29.

Shivdasani, A., \& Yermack, D. (1999). CEO involvement in the selection of new board members: An empirical analysis. The journal of finance, vol.54:5, pp.1829-1853.

Siskind, G. (1966). Mine Eyes have seen a host of Angels. American Psychologists, Vol. 21, pp. 404-406 Snyder, M., Tanke, E. D., \& Berscheid, E. (1977). Social perception and interpersonal behavior: On the self-fulfilling nature of social stereotypes. Journal of Personality and social Psychology, vol.35:9, p.656.

Snyder, M., Tanke, E. D. \& Berscheid, E. (January 01, 1977). Social Perception and Interpersonal Behavior: On the Self-Fulfilling Nature of Social Stereotypes. Journal of Personality and Social Psychology, vol.35:9, pp.656-666. 
Solway, K. S., Mock, L. T., Bostick, R. \& Reck, J. J. (1977). Psychologists' Descriptions of Female and Male Internship Applications. APIC Newsletter, vol.3:1, pp.24-27.

Sparrow, P. R. (2007). Globalization of HR at Function Level: Four UK-Based Case Studies of the International Recruitment and Selection Process. The International Journal of Human Resource Management, vol.18:5, pp.845-867.

Thorndike, E. L. (1920). A Constant Error in Psychological Ratings. Journal of Applied Psychology, vol.4, pp.25-29.

Tweedie, D., Wild, D., Rhodes, C. \& Martinov-Bennie, N. (2018). How Does Performance Management Affect Workers? Beyond Human Resource Management and Its Critique. International Journal of Management Reviews.

Tziner, A. \& Rabenu, E. (2018). Ways to improve the performance appraisal system 1: Rater training. In Improving Performance Appraisal at Work. Edward Elgar Publishing.

Van der Zee, K. I., Bakker, A. B. \& Bakker, P. (2002). Why are structured interviews so rarely used in personnel selection? Journal of Applied Psychology, vol.87:1, p.176.

Z. B. Junaid is Researcher in the Economics Academy, Wuhan, China.

Muhammad Siddique is an Assistant Professor in the Pakistan Navy School of Logistics, PNS Karsaz, Karachi.

Mariya Baig is an Assistant Registrar in the Department of Examination, University of Karachi. 